\title{
ANALYZING LABOR HETEROGENEITY IN GHANAIAN COCOA PRODUCTION AND ITS IMPLICATIONS FOR SEPARABILITY IN HOUSEHOLD DECISIONS AND POLICY ASSESSMENT
}

\author{
FRANCIS TSIBOE* \\ Agricultural Economics Department, Kansas State University, Manhattan, Kansas \\ JEFF LUCKSTEAD \\ Department of Agricultural Economics and Agribusiness, University of Arkansas, Fayetteville, Arkansas \\ BRUCE L. DIXON \\ Department of Agricultural Economics and Agribusiness, University of Arkansas, Fayetteville, Arkansas \\ LAWTON L. NALLEY \\ Department of Agricultural Economics and Agribusiness, University of Arkansas, Fayetteville, Arkansas \\ JENNIE S. POPP \\ Department of Agricultural Economics and Agribusiness, University of Arkansas, Fayetteville, Arkansas
}

\begin{abstract}
Researchers have employed farm household models (FHMs) for policy analysis under the separability assumption. However, separability can fail, and the household's production and consumption decisions become simultaneous. Using 5 years of household data, the separability assumption among Ghana's cocoa-producing households is tested via heterogeneity of household adult males and females, household children, and hired and exchange labor. Results show labor is heterogeneous, implying a lack of separability. Simulation analysis also shows that ignoring nonseparability leads to an underestimation of policy effects. Thus, nonseparability in production and consumption decisions must be incorporated in FHMs developed for Ghanaian cocoa-producing households.
\end{abstract}

Keywords. Cocoa Policy, Separability, Labor, Ghana, Farm Household Models

JEL Classifications. Q12, J31, J24, D13

The authors gratefully acknowledge the Centre for the Study of African Economies for making the Ghana Cocoa Farmers Survey data set available for public use. All errors and omissions are the responsibility of the authors.

*Corresponding author’s e-mail: ftsiboe@hotmail.com 


\section{Introduction}

Historically, researchers have employed farm household models (FHMs) to examine (1) the impact of alternative policies on farm household welfare, (2) the response by farm households to policies, and (3) market effects of policies targeted at farm households and spillover into other segments and subpopulations of the economy (Dillon and Barrett, 2017; Singh, Squire, and Strauss, 1986). Conventionally, FHMs have been solved sequentially (i.e., first, farm income is determined under conditions of profit maximization, and then the household utility is maximized subject to its budget constraint, which consists of the optimal farm income and total household time valued at the market wage rate). Thus, the conventional FHM implicitly assumes separability in household production and consumption decisions. However, in low-income economies, the key conditions that allow for separability typically break down, and the household's production and consumption decisions become simultaneous (Dillon and Barrett, 2017; Jorgenson and Lau, 2000; LaFave and Thomas, 2016; Singh, Squire, and Strauss, 1986).

When separability in the FHM breaks down, it changes comparative statics and results in inconsistent parameter estimates. For instance, even if the underlying utility and production functions are correctly specified, incorrectly assuming separability implies elasticity estimates are inconsistent. This occurs because shadow prices are erroneously treated as exogenous, like market prices (Singh, Squire, and Strauss, 1986). Shadow prices enable households to equate their demand and supply for commodities with missing markets and are not exogenous for each household as are market prices (Deaton and Muellbauer, 1980; Neary and Roberts, 1980). Furthermore, shadow prices are a function of utility, fixed inputs, time endowment, and market prices; thus, they are influenced by household behavior. Conversely, changes in market prices could affect households' behavior directly and indirectly through changes in shadow prices (Singh, Squire, and Strauss, 1986).

Two main conditions that lead to the breakdown of FHM separability cited in the literature are (1) incomplete and noncompetitive markets (Benjamin, 1992; Dillon and Barrett, 2017; LaFave and Thomas, 2016) and (2) imperfect substitution between family and hired labor in the farm production process (i.e., labor heterogeneity) (Deolalikar and Vijverberg, 1987; Singh, Squire, and Strauss, 1986). Although the former is the most common condition for the breakdown of separability, many studies have revealed that both market imperfections and labor heterogeneity also can lead to the breakdown of separability. These studies compare an implied marginal value product of labor versus observable market wages via estimating either production or cost functions (Bhattacharyya and Kumbhakar, 1997; de Janvry and Sadoulet, 2006; Jacoby, 1993; Lambert and Magnac, 1994; Skoufias, 1994).

According to Deolalikar and Vijverberg (1987), the separability between the consumption and production decisions in FHMs is generally justified based 
on the grounds of a perfectly competitive labor market and homogeneity of household and hired labor. If labor is homogeneous and labor markets are complete and competitive, then farm households are assumed to allocate labor independently of on-farm labor demand. Thus, excess household labor is sold via the labor market, or unmet labor for farming can be filled by hired labor at a single market wage rate. On the contrary, if household and hired labor are imperfect substitutes, then the demand and supply of labor by farm households become interlinked; thus, the household labor supply will depend on the demand for farm labor for tasks such as supervisory and managerial roles, which cannot be met by hired labor (Deolalikar and Vijverberg, 1987).

Consequently, labor heterogeneity may result in the marginal value product of labor not equaling the market wage rate. Thus, the level of labor heterogeneity could have critical implications for the validity of FHMs. Labor heterogeneity can stem from (1) labor qualifications and tasks (e.g., planting, harvesting, etc.), (2) seasonality in labor usage, (3) nonexistence of markets for different labor categories (particularly for child and female labor), (4) limited work hours because of labor market constraints (particularly unemployment), and (5) the need for supervision of hired labor (de Janvry and Sadoulet, 2006; Frisvold, 1994).

In their studies, Jacoby (1993) and Skoufias (1994) rejected equality between wage and marginal value product of labor by regressing a derived measure of the marginal value product of labor on observed wages (earned mainly by men) for households in Peru and India. By rejecting equality between wage and marginal productivity of labor, Jacoby (1993) and Skoufias (1994) show that production and consumption decisions are nonseparable. Lambert and Magnac (1994) developed a methodology to measure the average value and the standard deviation of the implicit wage (marginal value product of labor) of family labor and compared it with the wage offered. Using this methodology, households were classified based on whether separability holds. Applying this strategy to the living standards measurement study for Côte d'Ivoire, Lambert and Magnac (1994) rejected equality between the marginal value products of labor and wage for $90 \%$ of men but only for $50 \%$ of women. In another study, Bhattacharyya and Kumbhakar (1997) used an indirect production function on Indian rice producers to illustrate distortions in labor and draft animals relative to other inputs. They found that larger farms undervalue labor and draft animals more than smaller farms.

Although labor heterogeneity and separability in production and consumption decisions among farm households have been extensively studied, the literature on the subject matter regarding cocoa-producing households does not exist. Cocoa (Theobroma cacao) is the most valued agricultural commodity exported from West Africa, estimated at approximately US\$7 billion in 2012, and global cocoa consumption exceeded 4 million metric tons in the form of processed chocolate (United Nations Statistics Division, 2017). In 2013, estimates by the International 
Cocoa Organization (2014) indicated that Côte d'Ivoire accounted for $37 \%$ of all cocoa exports, followed by Ghana $(21 \%)$, and then Nigeria $(6 \%)$. Furthermore, more than $90 \%$ of the cocoa yielded in West Africa is produced by about 2 million peasant farmers on plots of up to 4 ha (World Cocoa Foundation [WCF], $2009,2014)$, and cocoa production accounts for $60 \%$ to $90 \%$ of the income of these farmers.

Although cocoa production provides income and employment for the producing households across West Africa, these households are plagued with issues such as poverty (the majority of households live on less than US\$2/day; WCF, 2012), low yields (relative to Asian and South American cocoa producers; Food and Agriculture Organization of the United Nations, 2017), and labor practices, which often involve children working on cocoa farms at the expense of attending school (International Cocoa Initiative, 2011). To minimize the occurrence of these issues, several development programs are being targeted at cocoa-producing households (WCF, 2018). Examples of such ongoing programs at the time of this study included Cocoa Action, Cocoa Livelihood Program (CLP), and the Harkin-Engel Protocol. Cocoa Action brings together leading cocoa and chocolate companies to foster sustainability and improve the livelihoods of cocoa farmers, CLP aims to double the income of cocoagrowing households, and the Harkin-Engel Protocol is aimed at ending child and forced labor used in cocoa production. To accurately estimate the impacts of these interventions, monitoring and evaluation teams must be inherently results oriented, using appropriate data and methods to support findings (United Nations Development Programme, 2009). Thus, information on labor heterogeneity and its implications for separability is needed to properly ascertain the impact of development programs through changes in both the production and consumption behavior of farm households.

Singh, Squire, and Strauss (1986) assert that modeling FHMs as separable or nonseparable is an issue that must be determined on a case-by-case basis. Thus, given the socioeconomic importance of cocoa globally and the level of interventions implemented in this sector, it is important to analyze labor heterogeneity in cocoa production and its implications for separability. Correctly specifying labor heterogeneity and accounting for separability are vital to accurately estimating the market and welfare impacts of development programs and policies. This study contributes to the existing literature in two important dimensions. First, using Ghana as a case study, the hypothesis of labor homogeneity in cocoa production in Ghana is tested while making no a priori assumptions on the substitution relationship among five different labor types used by cocoa farm households. A linearized Cobb-Douglas production function with a flexible translog function for labor aggregation is specified. Consequently, the parameter estimates are used to reveal the degree of heterogeneity among the five labor types to ascertain the existence of separability in consumption and production decisions among cocoa-producing households. Second, using 
the CLP development program as an example, the study simulates its effects in Ghana under both the separability and nonseparability assumptions on market prices and household welfare to illustrate the bias in results when separability is misspecified.

\section{Background Information}

\subsection{Cocoa Production in Ghana}

Cocoa is a perennial tree crop with an economically viable fruit-bearing life cycle of 25 to 30 years. Cocoa trees bear their first fruits typically in the fifth year after planting and reach full production capacity after 10 years. After 25 years, annual yields decline slowly over time, and the annual yield loss can be gradual, although the trees can live for 100 years (Lass, 2001). Cocoa thrives mostly in tropical rainforest zones with maximum annual average temperatures between $30^{\circ} \mathrm{C}$ and $32^{\circ} \mathrm{C}$, minimum annual average temperatures between $18^{\circ} \mathrm{C}$ and $21^{\circ} \mathrm{C}$, annual rainfall levels between $1,500 \mathrm{~mm}$ and $2,000 \mathrm{~mm}$, relative humidity as high as $100 \%$ during the day and $70 \%-80 \%$ during the night, and medium shade (Vigneri, 2008). Since its introduction in the 1880s, cocoa has become the mainstay of Ghanaian agriculture, providing the second largest export earnings for Ghana and accounting for about $30 \%$ of total exports (United Nations Statistics Division, 2017). As a cash crop with minimal domestic consumption, cocoa accounts for approximately $55 \%$ of the total income for cocoa-producing households in rural communities (Ghana Statistical Service [GSS], 2014).

Empirical studies have shown that Ghana's cocoa productivity, in terms of output per hectare $(\mathrm{kg} / \mathrm{ha})$, is mostly driven by labor use, technology (improved and hybrid varieties), land tenure (area expansion), nonlabor inputs use (mainly fertilizer, insecticide, and seedlings for replanting), and appropriate agricultural practices (Abenyega and Gockowski, 2003; Aneani and Ofori-Frimpong, 2013; School of Public Health and Tropical Medicine, Tulane University, 2015; Tsiboe and Nalley, 2016; Tsiboe et al., 2016; Vigneri, 2008; Zeitlin and Teal, 2006). Because the focus of the analysis is on labor heterogeneity, the following discussion focuses on labor use only.

Labor is a key input in cocoa production because it accounts for about $35 \%$ of the total value of inputs used in production following land (Centre for the Study of African Economies [CSAE], 2016; GSS, 2008, 2014; School of Public Health and Tropical Medicine, Tulane University, 2015). Labor employed in cocoa production in Ghana is broadly categorized into five types: (1) household adult male labor, (2) household adult female labor, (3) household child labor (less than 16 years), (4) exchange labor, and (5) paid labor (Abenyega and Gockowski, 2003; Zeitlin and Teal, 2006). Both adult male and female labor stem from the producer's own time, spouse's time, and adult extended family members' time. Household child labor is composed of labor provided by the producer's 
own children and those of other members of the extended family. Exchange labor, sometimes referred to as "reciprocal labor," is labor received from other producers and groups the farmer has joined.

According to Abenyega and Gockowski (2003), exchange labor involves adult workers only; however, in some cases, the producer may enlist the participation of family children. Paid labor consists of all nonfamily labor paid by cash, inkind, or through a sharecropping arrangement. Producers' own labor is the most frequently utilized labor type in cocoa production in Ghana (Abenyega and Gockowski, 2003). The five labor categories are employed in seven major tasks associated with cocoa production: (1) land preparation, (2) weeding and agrochemical application, (3) harvesting, (4) pod breaking, (5) field transport, (6) bean fermentation, and (7) fermented bean drying (Abenyega and Gockowski, 2003; Zeitlin and Teal, 2006). As shown by Abenyega and Gockowski (2003), the variation in the type and level of labor utilized in cocoa production is partly explained by household labor endowments, tasks, location (region), and size of the cocoa enterprise.

The Ghanaian cocoa market is partially liberalized, allowing private, licensed buying companies (LBCs) to purchase, sell, and transport cocoa. The LBCs sell to the Ghana Cocoa Board (COCOBOD) and local processing companies. The COCOBOD is the sole exporter and farm gate price regulator of Ghanaian cocoa. The COCOBOD sets the floor price for cocoa at about $70 \%$ of the net freeon-board price. This price setting regime enables COCOBOD to have working capital to stabilize the farm gate price and carry out its mandate.

\subsection{The Cocoa Livelihood Program}

The CLP is an ongoing developmental program (2009-2019) implemented in Ghana, Cote d'Ivoire, Nigeria, and Cameroon to double the income of approximately 200,000 cocoa-growing households. The objectives of CLP phase 1 implemented from February 2009 to January 2014 were to (1) increase cocoa production and quality at the farm level, (2) improve market efficiency and build capacity of farmers and farmer organizations, and (3) improve competitiveness by increasing farm diversification (Ndiaye, Budiansky, and Houston, 2013). In addition to improving cocoa yields, CLP phase 2 (February 2014 to January 2019) aims to bring about improvements in other food crops such as maize, cassava, and yams, which cocoa farmers grow simultaneously for household consumption. For a comprehensive description of the CLP see Tsiboe et al. (2016, 2018).

Farmers who participated in CLP phase 1 attended Farmer Field School (FFS) and Farmer Business School (FBS); subsequently, those farmers who completed both FFS and FBS and were deemed creditworthy were extended credit through an Input Credit Package (ICP) to obtain inputs (fertilizers and pesticide) for production. In Ghana, farmers received annual credit to purchase fertilizers subsidized at $36 \%$ of the market price. Applying the difference-in-differences 
modeling method to data collected from 700 pre- and post-CLP phase 1 surveys of Ghanaian cocoa farmers, Tsiboe et al. (2016) showed that cocoa yields for those farmers who completed both FFS and FBS and received ICP increased by $32 \%$.

\section{Methodology and Data}

The study develops an FHM for cocoa production in Ghana. Based the model, the empirical framework is specified, and a set of testable hypotheses connecting labor heterogeneity and nonseparability between consumption and cocoa production decisions is defined.

\subsection{Theoretical Model}

Cocoa is a nonconsumed cash crop; thus, all household production is surplus and is sold at the farm gate price set by COCOBOD, while the labor/leisure decision connects production with utility. Following Singh, Squire, and Strauss (1986), this study considers a representative Ghanaian cocoa-producing household that uses income from cocoa production and noncocoa activities to purchase all consumption goods. Thus, the household maximizes utility $(U)$ from the total consumption of goods $(G)$ and leisure $\left(L_{l}\right)$ of its members according to the monotonically increasing and quasi-concave utility function:

$$
U=U\left(G, L_{l} ; \boldsymbol{\alpha}\right),
$$

where $\boldsymbol{\alpha}$ is a vector of parameters. In the context of this study, leisure is defined as all time not allocated to cocoa production. The household produces cocoa according to the well-behaved production function $(\mathrm{Y})$ :

$$
Y_{c}=Y\left(L_{c}, x ; A, Z, \boldsymbol{\beta}\right),
$$

where $Y_{c}$ is total cocoa output, $L_{c}$ is total farm labor, $x$ is a nonlabor input, $A$ is land, $\mathrm{Z}$ is the productivity parameter, and $\boldsymbol{\beta}$ is a vector of output elasticities of inputs. Because of the perennial nature of cocoa trees with a 25- to 30-year life cycle, land $(A)$ is assumed to be fixed. Equation (1) is maximized subject to the cash income, labor use, and total time constraints:

$$
\begin{aligned}
P_{G} G & =P_{y} Y_{c}-w L_{b}-P_{x} x+E, \\
L_{c} & =L\left(L_{b}, L_{f} ; \rho\right), \\
T & =L_{l}+L_{f},
\end{aligned}
$$

where $P_{G}, P_{y}, w$, and $P_{x}$ are the prices of the consumption good, cocoa, labor (wage rate), and nonlabor input, respectively. The variable $E$ represents all other noncocoa-generated income. Equation (3) sets total spending equal to total profit from cocoa farming and noncocoa income. Total labor used in cocoa production $\left(L_{c}\right)$ (equation 4$)$ is a composite of hired labor $\left(L_{b}\right)$ and family labor $\left(L_{f}\right)$, where 
$\rho$ is a vector of parameters. Equation (5) sets the total household time availability $(T)$ to equal time spent on leisure $\left(L_{l}\right)$ and cocoa farming $\left(L_{f}\right)$.

In a standard FHM, $L_{c}=L_{b}+L_{f}$; if $L_{b}$ is positive, then the farm requires more labor hours than the farm household can provide, and it hires off-farm labor. Conversely, if $L_{h}$ is negative, then the farm requires fewer labor hours than the farm household would like to work, and the excess time is spent at off-farm work earning the market wage rate. Given the study tests for labor heterogeneity, we move away from the linear relationship defined previously and specify $L_{c}=L\left(L_{b}, L_{f} ; \boldsymbol{\rho}\right)$, where $L_{b}$ is only hired labor. In this context, it is not possible to include off-farm labor, as it would not be identified; thus, off-farm labor is not considered in this model. Further justifications for not including offfarm labor in the model are the following: (1) only $27 \%$ of typical cocoa farm household's hours, with a 7-day recall period, is spent on working off the farm (School of Public Health and Tropical Medicine, Tulane University, 2015), and (2) the household level data collected and used in Section 3.2.1 (tests for labor heterogeneity) did not include off-farm work labor allocation

Substituting equations (2), (4), and (5) into equation (3) and simplifying gives the full-income constraint:

$$
P_{G} G=P_{y}[Y(\cdot)]-w L^{b}\left(L_{c}, T-L_{l} ; \boldsymbol{\rho}\right)-P_{x} x+E,
$$

where $L^{b}(\cdot)$ is hired labor expressed as a function of total labor $\left(L_{c}\right)$ and family labor $\left(T-L_{l}\right)$ in cocoa production. The left-hand side of equation (6) expresses total household expenditures on consumption goods, while the right-hand side is Becker's (1965) concept of full income, which consists of profits from cocoa and noncocoa income. The Lagrangian $(\mathcal{L})$ for maximizing utility subject to the full-income constraint is

$$
\mathcal{L}=U\left(G, L_{l}\right)+\lambda\left(P_{y} Y(\cdot)-w L^{b}(\cdot)-P_{x} x+E-P_{G} G\right) .
$$

The first-order conditions necessary to maximize the household's total utility are

$$
\begin{aligned}
& \frac{\partial U}{\partial G}=\lambda P_{G} ; \quad \frac{\partial U}{\partial L_{l}}=\lambda w \frac{\partial L^{b}}{\partial L_{l}} ; \quad \frac{\partial Y}{\partial L_{c}} P_{y}=w \frac{\partial L^{b}}{\partial L_{c}} \\
& P_{y} \frac{\partial Y}{\partial x}=P_{x} ; P_{G} G=P_{y} Y(\cdot)-w L^{b}(\cdot)-P_{x} x+E .
\end{aligned}
$$

In this study, separability occurs if the cross-partial derivatives for hired labor are zero $\left(\frac{\partial^{2} L^{b}}{\partial L_{l} \partial L_{c}}=\frac{\partial^{2} L^{b}}{\partial L_{c} \partial L_{l}}=0\right)$, which implies that the leisure decision does not affect the optimal total labor decisions and vice versa. Therefore, the functional form of $L\left(L_{b}, L_{f} ; \boldsymbol{\rho}\right)$ is crucial in determining if separability exists in the model. For example, consider two functional forms: linear and nonlinear. Under the assumption of perfect homogeneity between labor inputs (denoted by the superscript 0 ), we have that

$$
L^{0}\left(L_{b}, L_{f} ; \rho\right)=\rho_{0}+\rho_{1} L_{f}+\left(\rho_{1}-1\right) L_{b} .
$$


Solving for hired labor as a function of total cocoa labor $\left(L_{c}\right)$ and total family cocoa labor $\left(T-L_{l}\right)$ yields

$$
L^{b 0}(\cdot)=\frac{L_{c}-\rho_{0}-\rho_{1}\left(T-L_{l}\right)}{\rho_{1}-1} .
$$

Therefore, the partial derivatives of $L^{b 0}(\cdot)$, with respect to leisure $L_{l}$ and total labor $L_{c}$, are

$$
\frac{\partial L^{b 0}}{\partial L_{l}}=\frac{\rho_{1}}{\rho_{1}-1} ; \frac{\partial L^{b 0}}{\partial L_{c}}=\frac{1}{\rho_{1}-1} .
$$

Thus, with the assumption of perfect homogeneity among labor inputs, the cross-partial derivatives are zero. Therefore, separability is achieved because the leisure $\left(L_{l}\right)$ and total labor used in cocoa production $\left(L_{c}\right)$ are independent of each other.

The second functional form of $L\left(L_{b}, L_{f} ; \boldsymbol{\rho}\right)$ is nonlinear, which provides more flexibility in the formulation of total labor (denoted by the superscript ${ }^{\prime}$ ):

$$
L^{\prime}\left(L_{h}, L_{f} ; \boldsymbol{\rho}\right)=\rho_{0}+\rho_{1} L_{f}+\left(1-\rho_{1}\right) L_{b}+\rho_{2} L_{f} L_{b}
$$

Based on parameter restrictions, the study can formulate hypothesis tests for labor substitutability. Solving for hired labor as a function of total cocoa labor $\left(L_{c}\right)$ and total family cocoa labor $\left(T-L_{l}\right)$ yields

$$
L^{h^{\prime}}(\cdot)=\frac{L_{c}-\rho_{0}-\rho_{1}\left(T-L_{l}\right)}{\left(1-\rho_{1}\right)+\rho_{2}\left(T-L_{l}\right)} .
$$

The partial derivatives of $L^{h^{\prime}}(\cdot)$, with respect to $L_{i}$ and $L_{c}$, are

$$
\frac{\partial L^{b^{\prime}}}{\partial L_{l}}=\frac{\rho_{2}\left(L_{c}-\rho_{0}\right)+\rho_{1}\left(\rho_{1}-1\right)}{\left[\rho_{1}-1+\rho_{2}\left(L_{l}-T\right)\right]^{2}} ; \quad \frac{\partial L^{b^{\prime}}}{\partial L_{c}}=\frac{1}{\left(1-\rho_{1}\right)+\rho_{2}\left(T-L_{l}\right)} .
$$

From equation (13), the cross partials $\left(\frac{\partial^{2} L^{b}}{\partial L_{l} \partial L_{c}}=\frac{\partial^{2} L^{b}}{\partial L_{c} \partial L_{l}}=\frac{\rho_{2}}{\left[\rho_{1}-1+\rho_{2}\left(T-L_{l}\right)\right]^{2}}\right)$ are not equal to zero, which implies that labor inputs are not independent of each other. As a result, the separability conditions break down because production choices $\left(L_{c}\right)$ are dependent on consumption choices $\left(L_{l}\right)$ and vice versa. Consequently, if the cross-term parameter $\rho_{2}$ equals zero, then hired and family labor can be considered perfectly homogeneous, and separability is achieved. Thus, the more substitutable each type of farm labor is, the more freely the farm household can adjust labor allocations and increase utility.

\subsection{Empirical Framework}

For illustrative proposes, Section 3.1 presented an oversimplified functional form for $L\left(L_{h}, L_{f} ; \boldsymbol{\rho}\right)$, and labor was divided into only two forms. Based on the theoretical model, the empirical strategy proceeds in two steps: First, an econometric model for testing the hypothesis of labor homogeneity in cocoa 
production is presented. Second, to ascertain the empirical implications, a simulation analysis of the impact of CLP on consumption and production input under the assumption of labor homogeneity and heterogeneity is conducted.

\subsubsection{Econometric Model}

This study estimates a reduced form model for the hypothesis test of labor homogeneity-unlike Deolalikar and Vijverberg (1987) who estimated two separate models for the production function (equation 2) and the composite total labor (equation 12). The empirical analysis considers a linearized Cobb-Douglas production function for equation (2) and the more robust translog specification for composite total labor (equation 12). The translog function is well established in the literature to allow for an unrestricted substitution relationship between factors of production (Berndt and Christensen, 1973; Bigsby, 1995; Binswanger, 1974; Corbo and Meller, 1979).

Additionally, unlike previous studies (D’Antoni, Khanal, and Mishra, 2014; Deolalikar and Vijverberg, 1987) that tested labor homogeneity between only household and nonhousehold, this study goes a step further by also testing labor homogeneity among all the five types of labor utilized in Ghanaian cocoa production. Thus, the estimation of the production function was done twice: once for aggregated household (household adult male, household adult female, and household child) and nonhousehold (exchange and paid) labor, and then once again for all the five types of labor utilized in Ghanaian cocoa production. The estimated parameters are then used to test the hypothesis that homogeneity exists among the different types of labor used by cocoa-farming households in production.

The outcome variable for the production function is the natural log of cocoa yield measured in $\mathrm{kg} / \mathrm{ha}\left(\mathrm{Y}_{\mathrm{kt}}\right)$ for the $k$ th household in period $t$. The reduced form of equation (2) and the translog specification for equation (12) is then specified for the econometric model as

$$
\ln \left[\mathrm{Y}_{\mathrm{kt}}\right]=\delta_{0}+g\left(\boldsymbol{L}_{k t}: \boldsymbol{\delta}_{x}\right)+\boldsymbol{\delta}_{X} \boldsymbol{X}_{k t}+\boldsymbol{\delta}_{H} \boldsymbol{H}_{k t}+\boldsymbol{u}_{k}+\varepsilon_{k t},
$$

where $g\left(L_{k t}: \delta_{x}\right)$ is the translog specification for equation (12), and $L_{k t}$ is a vector containing the type and amount-measured in man-day/ha-of labor used by the $k$ th household in period $t$. The vectors $\boldsymbol{X}_{\boldsymbol{k} t}$ and $\boldsymbol{H}_{k t}$ contain nonlabor inputs (fertilizer, insecticide, fungicide, production equipment, and assets) and other control variables for production (farm characteristics, household characteristics, growing season, and location).

In equation (15), $u_{k}+\varepsilon_{k t}$ is a composite error term such that $u_{k}$ is householdspecific and $\varepsilon_{k t}$ is assumed to be normally distributed with mean zero and finite variance. Given the assumption about the unobserved household-level effect $u_{k}$, equation (15) can be estimated as a random or fixed effects model. However, a Hausman test rejected a random effects model in favor of fixed effects model. Consequently, $u_{k}$ is modeled as a fixed effect. 
To ascertain if the labor types are homogeneous, the null hypotheses $\delta_{i j}=0$, where $i \neq j$, are tested. Subsequently, the estimated parameters for the labor variables are then used to calculate a partial elasticity of substitution based on Allen (1938) for each household to determine the degree of substitution or complementarity among labor types. The partial elasticity of substitution $\left(\sigma_{i j z t}\right)$ between any two labor types $i$ and $j$ for households located in location $z$ at time $t$ is defined by

$$
\sigma_{i j z t}=\frac{\sum_{i}^{5} f_{i} L_{i z t}}{L_{i z t} L_{j k t}} \cdot \frac{H_{i j z t}}{\left|H_{z t}\right|} ; \quad i \neq j ; \quad H_{z t}=\left[\begin{array}{cccc}
0 & f_{1 z t} & \cdots & f_{5 z t} \\
f_{1 z t} & f_{11 z t} & \cdots & f_{15 z t} \\
\vdots & \vdots & & \vdots \\
f_{5 z t} & f_{51 z t} & \cdots & f_{55 z t}
\end{array}\right],
$$

where $f_{i z t}$ is the mean marginal product of labor type $i, f_{i j z t}$ is the mean crossmarginal product of labor type $i$ and $j, H_{z t}$ is the bordered Hessian matrix and $\left|H_{z t}\right|$ is its determinant, and $H_{i j k t}$ is the $i j$ th cofactor; these variables apply to all households located in location $z$ at time $t .^{1}$ Generally, $\sigma_{i j z t}$ is negative when $L_{i}$ and $L_{j}$ are complements and positive when they are substitutes (Allen, 1938).

Given the log-log relationship between the outcome variable and labor, the output elasticity for the $i$ th type of labor for each household at time $t$ is estimated as

$$
\tau_{i k}=\frac{\partial \mathrm{Y}_{\mathrm{kt}}}{\partial L_{i k t}} \cdot \frac{L_{i k t}}{\mathrm{Y}_{\mathrm{kt}}}=\hat{\delta}_{i}+2 \hat{\delta}_{i i} L_{i k t}+\sum \hat{\delta}_{i j} L_{j k t} .
$$

Given the output elasticities of the types of labor, quantities of labor used in production by the $j$ th household in period $t$, and the price of cocoa $\left(P_{y t}\right)$ at period $t$, the respective marginal revenue product (implied wage) for the types of labor and household can be estimated by substituting the values of the estimated parameters $\left(\hat{\delta}_{i}, \hat{\delta}_{i i}\right.$, and $\left.\hat{\delta}_{i j}\right)$ from equation (15) and equation (17). The marginal revenue products $\left(V_{i k t}\right)$ for the $i$ th type of labor used by the $k$ th household in period $t$ are

$$
V_{i k t}=\tau_{i k} \frac{\mathrm{Y}_{\mathrm{kt}}}{L_{i k t}} \cdot P_{y t} .
$$

Following previous studies (Bhattacharyya and Kumbhakar, 1997; de Janvry and Sadoulet, 2006; Jacoby, 1993; Lambert and Magnac, 1994; Skoufias, 1994), the $V_{i k t}$ values are then regressed on categorical variables such as fixed effects for labor type $I_{i}$, growing season $G_{t}$, and household $F_{k}$ to determine if these are statistically different across the five labor types.

$$
V_{i k t}=\gamma_{0}+\boldsymbol{\gamma}_{I} I_{i}+\boldsymbol{\gamma}_{T} \boldsymbol{G}_{t}+\boldsymbol{\gamma}_{F} \boldsymbol{F}_{k} .
$$

\footnotetext{
${ }^{1}$ Note that the $i j$ th cofactor of a matrix is defined as the determinant of the matrix where the $i$ th row and $j$ th column are removed times $(-1)^{i+j}$.
} 


\subsubsection{Simulation Strategy}

Based on the results from the aggregated estimation of equation (15), a simulation analysis of CLP is carried out to find how misspecification of labor heterogeneity affects the magnitude and directional effects of key endogenous variables such as price, production, consumption, and household welfare. An abridged version of the simulation methodology is presented here; however, a detailed version is outlined in Note A1 provided in the online supplementary appendix.

The CLP simulation model considers a representative cocoa household that maximizes utility (equation 1) from the consumption of goods and leisure subject to the full-income constraint indicated by equation (6), where the labor aggregation function is given as equation (12). Additionally, the household is assumed to face a residual cocoa demand function representing Ghana's share of the world market. The parameters and exogenous variables in the model are calibrated to match the prices and output levels in 2010 following Tsiboe et al. (2018); Note A1 in the online supplementary appendix provides details on the model and its calibration.

The model is simulated for the cases of separability $\left(\rho_{2}=0\right)$ and nonseparability $\left(\rho_{2} \neq 0\right)$ over two scenarios: the baseline scenario before CLP and the alternate scenario after the CLP is implemented. Note that in this section, in the interest of simplification, $\rho_{2}$ is estimated for aggregated household labor. In the baseline scenario, the cocoa productivity parameter $(Z)$ in equation $(2)$ and the price of the nonlabor cocoa input $\left(P_{x}\right)$ are set equal to their calibrated values. In the alternate scenario, the productivity parameter and price of the nonlabor input are set to $Z(1+\emptyset)$ and $P_{x}(1-\sigma)$, respectively. Based on Tsiboe et al. (2016, 2018), $\varnothing=0.32$ is the productivity shock because of CLP training, and $\sigma=0.36$ is the nonlabor input subsidy received upon completion of the CLP program. Comparing the levels of key endogenous variables for the baseline and alternate scenarios for both the separable and nonseparable cases, we quantify the magnitude and directional effects of the two contrasting separability assumptions.

Before moving on, some caveats are noted. First, the literature asserts that it is critical for empirically estimated production functions to satisfy theories in microeconomics (i.e., quasi-concavity and monotonicity) (Sauer, Frohberg, and Hockmann, 2006), as this influences estimation of farmer specific outcomes. Consequently, failure to do so could compromise reasonable results interpretation (Henningsen and Henning, 2009; O'Donnell and Coelli, 2005). In this study, all input elasticities were positive; thus, monotonicity can be assumed to have been satisfied for the empirical model. However, a potential pitfall is that the empirical model may not exhibit the properties of quasi-concavity because it was a reduced form Cobb Douglas production and translog labor function. Second, the study ignores cocoa smuggling (both in and out of Ghana), partly because of the lack of statistics to accurately model these black-market outcomes. Depending on the direction of the smuggling, the price effects maybe more or less. However, the core finding of differing simulated policy outcomes based on 
the separability assumption is likely not affected by smuggling. Nevertheless, as a first approximation, the generated results can still provide insights into the separability of the production and consumption decisions among Ghanaian cocoa-producing households.

\subsection{Data}

The household-level data used to estimate equation (15) were collected from the Ghana Cocoa Farmers Surveys. The first round of surveys were conducted in 2002, with follow-up surveys conducted in 2004, 2006, 2008, and 2010, resulting in 5 years of quasi-panel data, albeit not a complete panel. The 2002 sample consists of randomly selected households from 25 villages throughout the cocoa-growing region of Ghana. The villages were selected with probabilities proportional to the size of the cocoa-farming population in each village. The sampling unit within a given village was taken as representative farmers within households. For the successive rounds, where the farmer interviewed for the previous survey had migrated to another city or village, the current primary owner of the farm at the time of the survey was interviewed. Where this failed, additional households were sampled. A similar strategy was implemented in 2004, 2006, 2008, and 2010. The data sets are available for public use from CSAE (2016). The final data used in this study are composed of 1,873 observations.

Table 1 provides summary statistics of selected variables in the estimation sample, which is composed of 1,873 observations. The summary statistics indicate households average about four members in adult equivalence $(\mathrm{AE})$, about $16 \%$ of whom are female headed. Household size in terms of AE is computed by dividing the total energy requirements of the household by $2,900 \mathrm{kcal}$, the energy requirements of an adult male between the ages of 19 and 50 years. $^{2}$ On average, the head of the household attended 8.5 years of school. For cocoa producers, the average farm size is 2.8 ha with an annual yield of $635 \mathrm{~kg} / \mathrm{ha}$. On average, cocoa farmers apply $58 \mathrm{~kg} / \mathrm{ha}$ of fertilizer, $0.3 \mathrm{~L} / \mathrm{ha}$ of pesticide, and $6.5 \mathrm{~kg} / \mathrm{ha}$ of fungicide annually. Annual average total labor usage is 160 man-hours/ha/season.

Table 2 provides a summary of the cocoa labor use dynamics within the producing households. The table shows that total cocoa labor is composed of about $40 \%$ provided by hired labor, $55 \%$ by the household (32\% from men, $20 \%$ from women, and $3 \%$ from children), and $5 \%$ by exchange labor. Household adult male labor is the dominant labor type used in land preparation, planting, cocoa husbandry, input application, and harvesting. In terms of prevalence, household adult male labor is followed by hired labor for activities pertaining to

\footnotetext{
2 The National Research Council (1989) calorie-based scale of AE has been commonly applied in nutritional studies in Ghana. The scale recognizes, for example, that the energy requirements for the young are less than that of the elderly. It also recognizes energy requirement differences along gender lines.
} 
Table 1. Descriptive Statistics of Selected Variables for Cocoa-Producing Households in Ghana from 2002 to 2010

\begin{tabular}{|c|c|c|c|}
\hline Variable & Mean & Standard Deviation & Trend \\
\hline Household size (AE) & 4.285 & 1.999 & 0.000 \\
\hline Household head (female $=1$ ) & 0.159 & 0.366 & $0.160^{* * *}$ \\
\hline Household head age (years) & 53.250 & 14.777 & $0.023^{* * *}$ \\
\hline Household head education (years) & 8.555 & 5.708 & 0.000 \\
\hline Credit access $($ yes $=1)$ & 0.247 & 0.431 & $0.324^{* * *}$ \\
\hline Share of cocoa land owned ( $\%)$ & 0.896 & 0.278 & $0.025^{* * *}$ \\
\hline Cocoa area (ha) & 2.766 & 2.847 & 0.007 \\
\hline New cocoa tress planted $($ yes $=1$ ) & 0.536 & 0.499 & $0.650^{* * *}$ \\
\hline Cocoa yield (kg/ha) & 635.275 & 407.106 & $0.035^{* * *}$ \\
\hline Fertilizer usage (kg/ha) & 58.127 & 145.544 & 0.029 \\
\hline Insecticide usage (L/ha) & 0.263 & 1.859 & 0.081 \\
\hline Fungicide usage (kg/ha) & 6.528 & 13.869 & $-0.379^{* * *}$ \\
\hline Total labor (man-day/ha) & 159.929 & 290.068 & $-0.126^{* * *}$ \\
\hline Cocoa farming equipment (index) ${ }^{\mathrm{a}}$ & 0.057 & 0.079 & $-0.228^{* * *}$ \\
\hline Born in community (yes $=1$ ) & 0.457 & 0.498 & - \\
\hline Migrant (yes $=1$ ) & 0.094 & 0.292 & - \\
\hline Not born in community (yes $=1$ ) & 0.449 & 0.498 & - \\
\hline $2001 / 2002$ season $($ yes $=1)$ & 0.194 & 0.396 & - \\
\hline $2003 / 2004$ season $($ yes $=1)$ & 0.202 & 0.402 & - \\
\hline $2005 / 2006$ season $($ yes $=1)$ & 0.190 & 0.392 & - \\
\hline $2007 / 2008$ season $($ yes $=1)$ & 0.194 & 0.396 & - \\
\hline $2009 / 2010$ season $($ yes $=1$ ) & 0.219 & 0.414 & - \\
\hline
\end{tabular}

${ }^{a}$ Index estimated via principal component analysis to capture the level of cocoa farming equipment ownership in each household. Higher values indicate a higher level of cocoa farming equipment ownership. Note: Sample size $=1,873$. AE, adult equivalence.

Source: Estimated by authors using household data from Centre for the Study of African Economies (2016).

land preparation, cocoa husbandry, and input application; and household adult female labor for activities pertaining to planning and harvesting. The dominant activities within labor types are cocoa husbandry for hired and household adult male labor and harvesting for household adult female and child labor and exchange labor. Furthermore, the data also show that while positive, the five labor activities have different correlations with cocoa yield ( $\mathrm{kg} / \mathrm{ha})$, with harvesting and input application having the highest and lowest correlation, respectively. Given the differences in labor activities and correlation with cocoa yield, it is important to test for the heterogeneity of the five different labor types and heterogeneity's implications for FHM separability.

\section{Results and Discussion}

In this section, aspects of heterogeneity in cocoa farming are investigated using the results of the fixed effects estimation, output elasticities, implied wage rates, 
Table 2. Cocoa Labor Dynamics within Cocoa-Producing Households in Ghana, 2002-2010

\begin{tabular}{|c|c|c|c|c|c|}
\hline & Hired & $\begin{array}{l}\text { Household } \\
\text { Adult Male }\end{array}$ & $\begin{array}{l}\text { Household } \\
\text { Adult Female }\end{array}$ & $\begin{array}{l}\text { Household } \\
\text { Child }\end{array}$ & Exchange \\
\hline Labor used $($ yes $=1)$ & $0.674(0.469)$ & $0.712(0.453)$ & $0.666(0.472)$ & $0.148(0.356)$ & $0.183(0.386)$ \\
\hline Labor share $(\%)$ & $39.921(37.504)$ & $32.111(30.044)$ & $19.993(24.531)$ & $2.517(8.907)$ & $5.459(15.677)$ \\
\hline \multicolumn{6}{|c|}{ Labor use distribution within labor activity (\%) } \\
\hline Land preparation & $36.212(40.709)$ & $40.907(38.458)$ & $17.529(27.158)$ & $2.777(11.800)$ & $2.575(12.307)$ \\
\hline Planting & $17.242(32.641)$ & $46.809(37.360)$ & $31.302(33.860)$ & $3.058(11.861)$ & $1.589(9.488)$ \\
\hline Husbandry & $32.458(38.220)$ & $40.428(36.079)$ & $20.991(29.210)$ & $2.104(9.918)$ & $4.019(15.625)$ \\
\hline Input application & $23.417(38.624)$ & $53.736(41.588)$ & $19.725(31.463)$ & $1.694(8.987)$ & $1.427(9.789)$ \\
\hline Harvesting & $23.316(34.230)$ & $38.732(33.412)$ & $26.907(28.273)$ & $4.117(12.972)$ & $6.928(18.869)$ \\
\hline \multicolumn{6}{|c|}{ Labor activity distribution within labor type (\%) } \\
\hline Land preparation & $9.308(20.042)$ & $8.923(15.567)$ & $7.274(16.691)$ & $8.448(20.748)$ & $5.297(16.861)$ \\
\hline Planting & $3.020(9.607)$ & $8.740(15.490)$ & $10.588(19.741)$ & $8.482(20.282)$ & $2.398(11.230)$ \\
\hline Husbandry & $40.982(37.949)$ & $46.109(28.656)$ & $37.677(33.945)$ & $25.885(34.671)$ & $31.210(39.827)$ \\
\hline Input application & $4.500(12.979)$ & $8.275(13.294)$ & $5.138(11.373)$ & $4.355(13.966)$ & $3.001(12.201)$ \\
\hline Harvesting & $18.388(27.147)$ & $27.953(25.654)$ & $39.323(35.221)$ & $52.830(40.982)$ & $58.094(43.568)$ \\
\hline
\end{tabular}

Source: Estimated by authors using household data from Centre for the Study of African Economies (2016). 
Table 3. Aggregated Fixed Effect Regression Results for Cocoa-Producing Households in Ghana, 2002-2010

\begin{tabular}{|c|c|c|c|}
\hline & Coefficient $^{\mathrm{a}}$ & & Standard Error \\
\hline \multicolumn{4}{|l|}{ Labor (man-days/ha) } \\
\hline Nonhousehold (ln [man-days/ha]) [B] & $0.115^{* * *}$ & & 0.033 \\
\hline Household (ln [man-days/ha]) [B] & $0.079^{* * *}$ & & 0.031 \\
\hline$[\mathrm{A}] \times[\mathrm{A}]$ & -0.010 & & 0.008 \\
\hline$[\mathrm{B}] \times[\mathrm{B}]$ & $-0.023^{* * *}$ & & 0.009 \\
\hline$[\mathrm{A}] \times[\mathrm{B}]$ & $-0.008^{*}$ & & 0.005 \\
\hline Cocoa area $(\ln [\mathrm{ha}])$ & $-0.506^{* * *}$ & & 0.033 \\
\hline Fertilizer usage (ln [kg/ha]) & $0.021^{* * *}$ & & 0.007 \\
\hline Insecticide usage (ln [L/ha]) & 0.001 & & 0.014 \\
\hline Fungicide usage (ln [kg/ha]) & $0.100^{* *}$ & & 0.046 \\
\hline Cocoa farming equipment (index) ${ }^{\mathrm{b}}$ & $0.502^{* *}$ & & 0.209 \\
\hline New cocoa tress planted $($ yes $=1$ ) & $-0.129^{* * *}$ & & 0.032 \\
\hline Household head (female $=1$ ) & 0.110 & & 0.098 \\
\hline Education household head (ln [years]) & 0.034 & & 0.024 \\
\hline Credit use (yes = 1) & $-0.089^{* *}$ & & 0.037 \\
\hline Trend & $0.029^{*}$ & & 0.015 \\
\hline Constant & $4.520^{* * *}$ & & 0.744 \\
\hline Number of observations & \multicolumn{3}{|c|}{1,873} \\
\hline Number of households & \multicolumn{3}{|c|}{752} \\
\hline$R$-squared & \multicolumn{3}{|c|}{$25.93 \%$} \\
\hline Model significance & \multicolumn{3}{|c|}{$22.738^{* * *}$} \\
\hline Correlation between $u_{b t}$ and covariates & \multicolumn{3}{|c|}{-0.483} \\
\hline Hausman specification test ${ }^{c}$ & \multicolumn{3}{|c|}{$115.492^{* * *}$} \\
\hline
\end{tabular}

${ }^{a}$ Dependent variable is the $\log$ of cocoa yield in $\mathrm{kg} / \mathrm{ha}$.

${ }^{b}$ Index estimated via principal component analysis to capture the level of cocoa farming equipment ownership in each household. Higher values indicate a higher level of cocoa farming equipment ownership. ${ }^{c}$ Fixed effect is consistent under both $\mathrm{Ho}$ and $\mathrm{Ha}$, and Random effect is inconsistent under Ha, efficient under Ho.

Note: Significance levels: ${ }^{*} P<0.10 ;{ }^{* *} P<0.05$; ${ }^{* *} P<0.01$.

Source: Estimated by authors using household data from Centre for the Study of African Economies (2016).

and the partial elasticities of substitution. We then examine the implications of the econometric results in terms of separability of consumption and production decisions in the model through the CLP simulation results.

\subsection{Econometric Analysis}

Table 3 presents the coefficient estimates from the aggregated fixed effects estimation of equation (15). The estimates for the disaggregated model (i.e., for all five labor types) are presented in Table A1 in the online supplementary appendix. Overall, the $R$-squared value for the aggregated model indicates that the model explains $25.74 \%$ of the dependent variable variation. Additionally, the $F$-statistic indicates that the model is significant at $P<0.01$. 
Table 4. Output Elasticities and Implied Wage Specific Types of Labor for Cocoa-Producing Households in Ghana, 2002-2010

\begin{tabular}{lll}
\hline \hline Labor type & Elasticities & $\begin{array}{l}\text { Implied Wage } \\
(\text { US } \$ \text { man-day })^{\mathrm{a}, \mathrm{b}}\end{array}$ \\
\hline Aggregated model & & \\
Nonhousehold & $0.039^{* * *}(0.000)$ & $1.224^{* * *}(0.066)$ \\
Household & $0.053^{* * *}(0.001)$ & $2.138^{* * *}(0.233)$ \\
Disaggregated model & & $0.821^{* * * \mathrm{~A}}(0.069)$ \\
Hired & $0.027^{* * *}(0.001)$ & $1.446^{* * * \mathrm{~B}}(0.288)$ \\
Household adult male & $0.013^{* * *}(0.002)$ & $1.378^{* * * \mathrm{~B}}(0.111)$ \\
Household adult female & $0.015^{* * *}(0.000)$ & $0.842^{* * * \mathrm{~A}}(0.139)$ \\
Household child & $0.005^{* * *}(0.000)$ & $0.308^{* * \mathrm{C}}(0.148)$ \\
Exchange & $0.027^{* * *}(0.001)$ & \\
\hline \hline
\end{tabular}

${ }^{a}$ Implied wage indicated by the same superscript letters are not statistically $(P<0.05)$ different from one another. Pairwise comparisons of the implied wage are done using Bonferroni's adjustment.

${ }^{b}$ Values are in 2010 monetary terms.

Notes: Significance levels: ${ }^{*} P<0.10 ;{ }^{* *} P<0.05 ;{ }^{* * *} P<0.01$. Parentheses denote standard error.

Source: Estimated by authors using household data from Centre for the Study of African Economies (2016).

To ascertain the homogeneity of household and nonhousehold labor, the null hypothesis, $\delta_{i j}=0$, where $i=$ household and $j=$ nonhousehold, is tested. Thus, if the cross term between household and nonhousehold labor is statistically different from zero, then the separability condition breaks down. From Table 3, the estimated cross-term parameter for household and nonhousehold labor is significantly $(P<0.10)$ different from zero. The estimated cross-term parameters, excluding the cross term for hired and household adult female labor in Table A1 (online supplementary appendix), denoted as $[\mathrm{A}] \times[\mathrm{C}]$, have values that are not significantly different from zero. This implies hired and adult female labor cannot be considered as perfectly homogeneous. Therefore, the study concludes that production and consumption decisions among Ghanaian cocoa-producing households are not recursive and separable.

Additionally, the estimated output elasticities of labor, reported in Table 4, show that for the aggregated model, a $1 \%$ increase in the use of nonhousehold and household labor significantly $(P<0.01)$ increases cocoa yields by $0.039 \%$ and $0.053 \%$, respectively. When the model is estimated for all five types of labor, the elasticities are estimated at $0.027 \%, 0.013 \%, 0.015 \%, 0.005 \%$, and $0.027 \%$ for hired, household adult male, household adult female, household child labor, and exchange labor, respectively. Table 4 also reports the implied wages (marginal revenue product) of the five types of labor used in cocoa production. The results show household adult male labor has the highest marginal revenue product, estimated from equation (17), at US\$1.45/manday, followed by household adult female (US\$1.38/man-day), household child 
labor (US\$0.84/man-day), hired labor (US\$0.82/man-day), and exchange labor (US\$0.31/man-day). Given the magnitudes of the elasticities in Table 4, the size of the implied wage for child labor relative to hired labor is counterintuitive; however, further clarification is given via the sign and magnitudes of the partial elasticities of substitution discussed in the subsequent paragraph. A pairwise comparison of the implied wages for the five types of labor indicates that, except for (1) hired and child labor and (2) household adult female and child labor, equality of the implied wages for the other types of labor is significantly $(P<$ 0.01 ) rejected.

Table 5 displays the partial elasticities of substitution for the five labor types, which are estimated for each community and averaged across the sample to test their statistical significance. The estimated elasticities of substitution show that hired labor substitutes for household adult female labor but is a complement to household adult male labor, household child labor, and exchange labor. Specifically, if the cost of hired labor increases by $1 \%$, the use of household adult female labor will increase by $0.54 \%$. On the contrary, if the cost of hired labor increases by $1 \%$, the use of household adult male, child, and exchange labor will fall by $0.03 \%, 0.13 \%, 0.02 \%$, respectively. Household adult male labor substitutes for household adult female and child labor and complements exchange labor. Although hired, household adult female, and exchange labor are all complements with child labor, the strongest complementarity is between household adult female and child labor, with the latter decreasing by $9.66 \%$ for every $1 \%$ reduction in the cost of the former. Exchange labor is a substitute for household adult female labor and a complement to household adult male labor, with an estimated elasticity of $0.37 \%$. The partial elasticities of substitution combined with our findings on the $\delta_{i j}$ imply that little evidence exists to support the homogeneity among the five labor types.

The relationship between adult labor-particularly female-and child labor is consistent with the fact that women are usually the primary caregivers for the household children. Thus, women spend more time with children and are likely to take them along to the farm. Estimates from the sixth round of the Ghana Living Standards Survey (GSS, 2014) indicate that Ghanaian women spend about $31 \%$ more time caring for household children, relative to men from the same household. The complementarity of household adult female labor with child labor also offers insight into why the implied wage for child labor is high relative to both hired and household adult male labor. The intuition is that the implied wage for child labor is high because children are more likely to be found on the farm with the labor type (household adult female labor) that has the second highest implied wage. Thus, given that the responsiveness of cocoa yields to child labor was the lowest, the estimated implied wage for household children could be reflecting that of household adult female labor. Furthermore, a major proportion of child labor $(53 \%)$ ) engages in cocoa-harvesting activities, which is the labor activity that is most positively correlated with cocoa yield. Thus, coupled with 
Table 5. Partial Elasticity of Substitution among Labor Types Used by Cocoa-Producing Households in Ghana, 2002-2010

\begin{tabular}{llccc}
\hline \hline & & Household & Household & Household \\
Adult Female & & Child \\
\hline Household adult male & $-0.07^{\mathrm{a}}(0.018)[179]$ & - & - & - \\
Household adult female & $0.59^{\mathrm{b}}(0.542)[150]$ & $2.438^{\mathrm{b}}(1.096)[194]$ & - & - \\
Household child & $-0.126^{\mathrm{a}}(0.090)[46]$ & $3.803^{\mathrm{b}}(1.673)[68]$ & $-9.664^{\mathrm{a}}(9.165)[72]$ & - \\
Exchange & $-0.018^{\mathrm{a}}(0.006)[56]$ & $-2.130^{\mathrm{a}}(1.330)[78]$ & $0.374^{\mathrm{b}}(0.361)[84]$ & $-0.355^{\mathrm{a}}(0.355)[39]$ \\
\hline \hline
\end{tabular}

${ }^{a}$ Indicates labor pairs that are substitutes.

bIndicates labor pairs that are complements.

Notes: Significance levels: ${ }^{*} P<0.10 ;{ }^{* *} P<0.05$; ${ }^{* * *} P<0.01$. A negative value indicates that the respective labor types are complements and positive means they are substitutes. Parentheses denote standard errors, and brackets denote number of households.

Source: Estimated by authors using household data from Centre for the Study of African Economies (2016). 
its complementarity with household adult female labor, it is reasonable that the implied wage of household child labor is the third highest.

In terms of the other covariates, Table 3 indicates a $1 \%$ increase in farm size decreases production significantly by $0.51 \%$. For a $1 \%$ increase in the use of fertilizer and fungicide, cocoa yield increases by $0.02 \%$ and $0.10 \%$, respectively. Producers with young cocoa trees (ages 0 to 4 years) have significantly lower yields by $12.90 \%$. This follows logically because cocoa trees take 3 to 5 years to produce their first crop (Wood and Lass, 1987). The sign of the estimated, significant nonlabor coefficients are all consistent with existing studies on cocoa productivity in Ghana (Aneani and Ofori-Frimpong, 2013; Edwin and Masters, 2005; Tsiboe and Nalley, 2016; Tsiboe et al., 2016; Wood and Lass, 1987).

\subsection{Cocoa Livelihood Program Simulation Analysis}

Given the evidence of labor heterogeneity in the previous section, the study investigates the impact of assuming labor homogeneity by simulating CLP outcomes under assumptions of labor homogeneity and labor heterogeneity. The CLP simulation results, shown in Table 6, indicate that both the calibration of the parameters and simulation results are affected by the homogeneity assumption made on labor and, thus, separability in the FHM. Specifically, Table 6 shows that the calibrated production parameters for cocoa $\left(\beta_{1}\right.$ and $\left.Z\right)$ and the utility parameters $\left(\alpha_{1}\right.$ and $\left.\alpha_{2}\right)$ have varying degrees of sensitivity to the assumption made on labor homogeneity. Specifically, $\alpha_{1}, \alpha_{2}, \beta_{1}$, and $Z$ change by $-0.26 \%$, $17.78 \%, 27.72 \%$, and $-1.49 \%$, respectively. These sensitivities occur because

the calibration of these parameters depends on the partial derivative $\frac{\partial L^{b 0}}{\partial L_{l}}$ and $\frac{\partial L^{b 0}}{\partial L_{c}}$, which is directly affected by the labor assumption.

Table 6 reports simulation results for changes in cocoa production, cocoa price, farm household consumption, leisure, and welfare for both the separable model and nonseparable model. Here, we focus our discussion on how the separability assumption affects the simulation results; for a broader discussion of CLP and its market impacts, see Tsiboe et al. (2018). The simulation results indicate that incorrectly modeling labor types as homogeneous-in this case " $\mathrm{A}$ Separable Model"-also leads to underestimated simulation results in terms of the magnitude of the changes for consumption of goods and leisure because of the implementation of the CLP program. The model assuming homogeneity between labor types underestimates the magnitude of the change in the consumption of goods and leisure by $1.38 \%$ and $1.28 \%$, respectively. The intuition behind this underestimation-particularly leisure-is directly linked to the fact that the shadow prices for household labor are functions of the market wage rates and the partial derivative $\frac{\partial L^{b 0}}{\partial L_{l}}$ that is directly affected by the labor assumption.

Shadow prices enable households to equate their demand and supply for commodities with missing markets (Deaton and Muellbauer, 1980; Neary and Roberts, 1980) and are not exogenous. However, the separable model (with 
Table 6. Calibration and Simulation Results for Cocoa Livelihood Program (CLP) Implementation in Ghana

\begin{tabular}{|c|c|c|c|c|c|c|}
\hline & & Separable Model & & & Nonseparable Model & \\
\hline \multicolumn{7}{|l|}{ Calibrated Parameters } \\
\hline$\alpha_{1}$ & 0.983 & & & 0.986 & & \\
\hline$\alpha_{2}$ & 0.017 & & & 0.014 & & \\
\hline$\beta_{1}$ & 0.017 & & & 0.013 & & \\
\hline$\beta_{2}$ & 0.002 & & & 0.002 & & \\
\hline Z & 383 & & & 389 & & \\
\hline$\rho_{0}$ & 28.773 & & & 28.773 & & \\
\hline$\rho_{1}$ & 0.575 & & & 0.575 & & \\
\hline$\rho_{2}$ & 0.000 & & & 0.003 & & \\
\hline$T$ & 357 & & & 357 & & \\
\hline E & $-1,925$ & & & $-1,924$ & & \\
\hline$P_{G}$ & 1.703 & & & 1.703 & & \\
\hline$P_{x}$ & 1.000 & & & 1.000 & & \\
\hline$w$ & 0.116 & & & 0.116 & & \\
\hline$D$ & 1.330 & & & 1.330 & & \\
\hline I & 35863 & & & 35863 & & \\
\hline$\eta_{I}$ & 0.620 & & & 0.620 & & \\
\hline$\eta_{P}$ & -0.900 & & & -0.900 & & \\
\hline \multicolumn{7}{|l|}{ Simulation Results } \\
\hline & Cocoa $\left(Y_{c}\right)$ & Goods $(G)$ & Leisure $\left(L_{i}\right)$ & $\operatorname{Cocoa}\left(Y_{c}\right)$ & Goods $(G)$ & Leisure $\left(L_{i}\right)$ \\
\hline Price change $(\%)$ & -21.737 & - & - & -21.737 & - & - \\
\hline Production change (\%) & 32.000 & - & - & 32.000 & - & - \\
\hline Consumption change $(\%)$ & - & 1.068 & 1.068 & - & 1.083 & 1.082 \\
\hline Consumer surplus change (US\$) & 468.718 & 24.194 & - & 468.718 & 24.490 & - \\
\hline Producer surplus change (US\$) & 46.690 & - & - & 46.933 & - & - \\
\hline Net welfare change (US\$) & 537.265 & & & 537.804 & & \\
\hline
\end{tabular}

Notes: Simulation: Because of CLP, households experience a productivity shock (increase) of $32 \%$ and a subsidy of $36 \%$ on nonlabor inputs coupled with an income shock (increase) of $2.731 \%$ and demand expansion of $4.117 \%$ in the world cocoa market. 
homogeneous labor types) inherently treats the shadow prices for household labor as a constant that is equal to $w\left(\frac{\rho_{1}}{\rho_{1}-1}\right)$. This shadow price takes the same value of approximately $1.35 \mathrm{w}$ in both the baseline scenario (before CLP) and the alternate scenario (after CLP). Consequently, in the separable model, the shadow prices for household labor become higher than the market wage rate for hired labor. This causes the household to limit the use of household labor under increased productivity from the CLP program, ceteris paribus, which in turn frees up more household time to be consumed as leisure.

In contrast, the nonseparable model (with heterogeneous labor types) treats the shadow prices for household labor as a function of endogenous variables equal to $w\left(\frac{\rho_{2}\left(L_{c}-\rho_{0}\right)+\rho_{1}\left(\rho_{1}-1\right)}{\left[\rho_{1}+\rho_{2}\left(T-L_{l}\right)-1\right]^{2}}\right)$. Thus, the shadow prices take deferent values based on the scenario. Particularly, the shadow prices for both scenarios are calculated at $1.15 \mathrm{w}$ and $1.20 \mathrm{w}$ for the baseline (before CLP) and the alternate (after CLP) scenario, respectively. Thus, in addition to being higher than the market wage rate for hired labor, the shadow prices for household labor also become relatively higher in the alternate scenario. This causes the household to limit the use of household labor under increased productivity from the CLP program (relative to the baseline), ceteris paribus, which in turn frees up more household time for leisure than that of the separable model.

We now analyze the impact of the labor homogeneity assumption when assessing the impact of CLP on the welfare of cocoa-producing households. Under nonseparability, because farmers become more efficient following CLP, production increases. This, coupled with the global demand expansion in cocoa consumption, increases household cash income and good consumption. ${ }^{3}$ Therefore, consumer surplus for good $G$, as well as producer surplus from cocoa production, increases because of the implementation of CLP. Both surpluses serve as household-level welfare indicators. However, under the assumption of separability, the changes are underestimated. Specifically, the change in consumer surplus for good $G$ and producer surplus is $1.22 \%$ and $0.52 \%$ higher in the nonseparable model relative to the separable model. In net, the gains in consumer and producer surplus from cocoa production exceed the total CLP cost, and the change in new welfare is positive. The total cost of CLP per farmer who benefited directly from the program was estimated at US\$151 in 2010 terms (Tsiboe et al., 2016).

\section{Concluding Remarks}

Cocoa production provides employment and $60 \%-90 \%$ of the income of the producing households across West Africa; however, most of these households are plagued with issues such as poverty, low yields, and child labor. Several programs,

3 Cocoa demand was expanded to reflect the increasing consumer preference for darker chocolate and the growing Asian middle class, which is consuming more chocolate. 
like the CLP, have been targeted at cocoa-producing households to minimize the occurrence of these issues. However, predicting and measuring the impact of such development policies is complex, and the spillover effects into other sectors can be difficult to measure. Thus, the impact of any policy that acts as a catalyst for change in the agricultural sector must be evaluated through changes in both the production and consumption behavior of farm households. Traditionally, monitoring and evaluation researchers have used the FHM to analyze the policy effects on the well-being of farm households and spillover effects into other sectors.

Conventional FHMs assume separability in production and consumption decisions, where farm income is first maximized by conventional conditions for profit maximization, then the household maximizes its utility subject to farm income. However, because of market imperfections (underdeveloped and/or absent markets) and labor heterogeneity, separability breaks down and the household's production and consumption decisions become simultaneous. Accordingly, this can affect empirical farm-household modeling by changing comparative static results and renders parameter estimates statistically inconsistent. It is, therefore, relevant to test for the presence of nonseparability before embarking on empirical modeling of farm households.

Based on the analysis, production and consumption decisions among Ghanaian cocoa-producing households are not recursive and separable. Additionally, the study demonstrates that when the breakdown of separability is not accounted for, the magnitude of the impact of simulation analyses that estimate the effects of development policies, such as the CLP, are inaccurate. The positive impacts associated with the CLP were underestimated when separability was assumed. Assuming separability when it does not exist could lead policy makers to undervalue agricultural support programs that contribute to improvements for households and potentially shift resources out of such programs into other activities that generate less positive benefits to society.

The sensitivity of yields to different types of labor is important. Cocoa yields are relatively more sensitive to hired and exchange labor, followed by household adult female labor, household adult male labor, and then household child labor. Further, hired labor complements (substitutes) household adult male (female) labor, suggesting that household adult males are responsible for the supervision of hired labor. Furthermore, given that household adult female labor complements child labor, policies aimed at educating households about child labor could be targeted to household women for greater impact. Because cocoa production in Ghana is a household business, children will always be found on the farms, as this facilitates transition of farm ownership from the old to the young generation. Although this is a cultural issue, women could be targeted with information about hazardous child labor activities as specified by Ghanaian law. These include clearing of forest or felling trees, working with agrochemicals, breaking cocoa pods with a breaking knife, climbing trees higher than $3 \mathrm{~m}$, and 
harvesting overhead cocoa pods with a harvesting hook. Moreover, given that a major proportion of child labor engages in cocoa-harvesting activities, child labor-reducing activities could be targeted and implemented during the harvest periods for cocoa.

Finally, the results highlight important implications of development programs such as CLP on the allocation of time to leisure. We find that, under separability, yield-enhancing policies like CLP result in the household spending more time at leisure; also, this result is magnified under nonseparability. However, more leisure (less work) does not imply that income falls, because yield increases more than offset price declines.

\section{References}

Abenyega, O., and J. Gockowski Labor Practices in the Cocoa Sector of Ghana with a Special Focus on the Role of Children: Findings from a 2001 Survey of Cocoa Producing Households. Ibadan, Nigeria: International Institute of Tropical Agriculture, 2003.

Allen, R.G.D. Mathematical Analysis for Economists. London: Macmillan, 1938.

Aneani, F., and K. Ofori-Frimpong. "An Analysis of Yield Gap and Some Factors of Cocoa (Theobroma cacao) Yields in Ghana.” Sustainable Agriculture Research 2,4(2013):11727.

Becker, G.S. “A Theory of the Allocation of Time.” Economic Journal 75,299(1965):493-517.

Benjamin, D. "Household Composition, Labor Markets, and Labor Demand: Testing for Separation in Agricultural Household Models." Econometrica 60,2(1992):287-322.

Berndt, E.R., and L.R. Christensen. "The Translog Function and the Substitution of Equipment, Structures, and Labor in U.S. Manufacturing 1929-68." Journal of Econometrics 1,1(1973):81-113.

Bhattacharyya, A., and S.C. Kumbhakar. "Market Imperfections and Output Loss in the Presence of Expenditure Constraint: A Generalized Shadow Price Approach.” American Journal of Agricultural Economics 79,3(1997):860-71.

Bigsby, H.R. "Production Structure and the Australian Sawmilling Industry." Australian Journal of Agricultural Economics 38,3(1995):271-88.

Binswanger, H.P. "A Cost Function Approach to the Measurement of Elasticities of Factor Demand and Elasticities of Substitution." American Journal of Agricultural Economics 56,2(1974):377-86.

Centre for the Study of African Economies. "Ghana Cocoa Farmers Survey Data.” 2016. Internet site: http://www.csae.ox.ac.uk/general/csae-ghana-cocoa-data (Accessed May $8,2018)$.

Corbo, V., and P. Meller. "The Translog Production Function: Some Evidence from Establishment Data." Journal of Econometrics 10,2(1979):193-99.

D’Antoni, J.M., A.R. Khanal, and A.K. Mishra. "Examining Labor Substitution: Does Family Matter for U.S. Cash Grain Farmers?” Journal of Agricultural and Applied Economics 46,2(2014):273-84.

Deaton, A., and J. Muellbauer. Economics and Consumer Behavior. Cambridge: Cambridge University Press, 1980.

de Janvry, A., and E. Sadoulet. "Progress in the Modeling of Rural Households' Behavior under Market Failures." Poverty, Inequality and Development. A. de Janvry and R. Kanbur, eds. Boston, MA: Kluwer, 2006, pp. 115-82. 
Deolalikar, A.B., and W.P.M. Vijverberg. "A Test of Heterogeneity of Family and Hired Labour in Asian Agriculture." Oxford Bulletin of Economics and Statistics 49,3(1987):291305.

Dillon, B., and C.B. Barrett. “Agricultural Factor Markets in Sub-Saharan Africa: An Updated View with Formal Tests for Market Failure." Food Policy 67(February 2017):64-77.

Edwin, J., and W.A. Masters. "Genetic Improvement and Cocoa Yields in Ghana." Experimental Agriculture 41,4(2005):491-503.

Food and Agriculture Organization of the United Nations. "FAOSTAT.” 2017. Internet site: http://faostat.fao.org/ (Accessed February 20, 2018).

Frisvold, G.B. "Does Supervision Matter? Some Hypothesis Tests Using Indian Farm-Level Data." Journal of Development Economics 43,2(1994):217-38.

Ghana Statistical Service (GSS). Ghana Living Standard Survey 5: 2005, With Non-Farm Household Enterprise Module. Accra, Ghana: GSS, 2008.

- Ghana Living Standards Survey 6 (with a Labour Force Module) 2012-2013, Round Six. Accra, Ghana: GSS, 2014.

Henningsen, A., and C.H.C.A. Henning. "Imposing Regional Monotonicity on Translog Stochastic Production Frontiers with a Simple Three-Step Procedure." Journal of Productivity Analysis 32,3(2009):217-29.

International Cocoa Initiative. Cocoa Farming: An Overview. 2011. Internet site: http://www.cocoainitiative.org/wp-content/uploads/2016/09/ECA_-_2011_-_Cocoa_ Farming_an_overview.pdf (Accessed February 20, 2018).

International Cocoa Organization (ICCO). Annual Report 2012/2013. London: ICCO, 2014. Internet site: https://www.icco.org/about-us/international-cocoa-agreements/ doc_download/1311-annual-report-2012-2013-english-french-spanish-russian.html (Accessed February 20, 2018).

Jacoby, H.G. "Shadow Wages and Peasant Family Labour Supply: An Econometric Application to the Peruvian Sierra." Review of Economic Studies 60,4(1993):903-21.

Jorgenson, D., and L.J. Lau. "An Economic Theory of Agricultural Household Behavior." Econometric Modeling of Producer Behavior. D.W. Jorgenson, ed. Cambridge, MA: MIT Press, 2000, pp. 97-124.

LaFave, D., and D. Thomas. "Farms, Families, and Markets: New Evidence on Completeness of Markets in Agricultural Settings.” Econometrica 84,5(2016):1917-60.

Lambert, S., and T. Magnac. "Measurement of Implicit Prices of Family Labour in Agriculture: An Application to Côte d'Ivoire." Agricultural Household Modelling and Family Economics. F. Caillavet, H. Guyomard, and R. Lifran, eds. New York: Elsevier, 1994, pp. 9-24.

Lass, R.A. "Replanting and Rehabilitation of Old Cocoa Farms." Cocoa. G.A.R. Wood and R.A. Lass, eds. Oxford: Blackwell Science, 2001, pp. 210-33.

National Research Council. Recommended Dietary Allowances. 10th ed. Washington, DC: National Academies Press, 1989.

Ndiaye, M., E. Budiansky, and H. Houston. Global Development Annual Progress Report: Cocoa Livelihoods Program. Washington, DC: World Cocoa Foundation, 2013.

Neary, J.P., and K.W.S. Roberts. "The Theory of Household Behaviour under Rationing." European Economic Review 13,1(1980):25-42.

O’Donnell, C.J., and T.J. Coelli. "A Bayesian Approach to Imposing Curvature on Distance Functions." Journal of Econometrics 126,2(2005):493-523.

Sauer, J., K. Frohberg, and H. Hockmann. "Stochastic Efficiency Measurement: The Curse of Theoretical Consistency.” Journal of Applied Economics 9,1(2006):139-66. 
School of Public Health and Tropical Medicine, Tulane University. 2013/14 Survey Research on Child Labor in the West African Cocoa Sector. New Orleans, LA: Tulane University, 2015. Internet site: http://www.childlaborcocoa.org/images/Payson_Reports/Tulane\% 20University \%20-\%20Survey\%20Research\%20on\%20Child\%20Labor \%20in \% 20the $\% 20$ Cocoa $\% 20$ Sector \%20-\%2030\%20July\%202015.pdf (Accessed February 20, 2018).

Singh, I., L. Squire, and J. Strauss. "A Survey of Agricultural Household Models: Recent Findings and Their Implications.” World Bank Economic Review 1,1(1986):1-44.

Skoufias, E. "Using Shadow Wages to Estimate Labor Supply of Agricultural Households." American Journal of Agricultural Economics 76,2(1994):215-27.

Tsiboe, F., B.L. Dixon, L.L. Nalley, J.S. Popp, and J. Luckstead. "Estimating the Impact of Farmer Field Schools in Sub-Saharan Africa: The Case of Cocoa." Agricultural Economics 47,3(2016):329-39.

Tsiboe, F., J. Luckstead, L. Nalley, B. Dixon, and J. Popp. "Market Effects of Farmer Field Schools in Sub-Saharan Africa: The Case for Cocoa." Review of Development Economics (2018).

Tsiboe, F., and L.L. Nalley. "Effect of Biotic and Abiotic Stress on Household Cocoa Yields in Ghana." African Journal of Agricultural and Resource Economics 11,3(2016):239-48.

United Nations Development Programme (UNDP). Handbook on Planning, Monitoring and Evaluating for Development Results. New York: UNDP, 2009. Internet site: http://web. undp.org/evaluation/guidance.shtml\#handbook (Accessed February 20, 2018).

United Nations Statistics Division. "United Nations Statistics Division - Commodity Trade Statistics Database (COMTRADE).” 2017. Internet site: https://comtrade.un.org/ (Accessed February 20, 2018).

Vigneri, M. "Drivers of Change in Ghana's Cocoa Sector." Ghana Strategy Support Program Background Paper No. 13, Washington, DC: International Food Policy Research Institute, 2008. Internet site: http://ebrary.ifpri.org/cdm/ref/collection/p15738coll2/id/ 18214 (Accessed February 20, 2018).

Wood, G.A.R., and R.A. Lass. Cocoa. Harlow, UK: Longman Scientific and Technical, 1987.

World Cocoa Foundation (WFC). Cocoa Livelihoods Program (CLP). Washington, DC: WFC, 2009. Internet site: http://www.cocoaconnect.org/sites/default/files/publication/ CocoaLivelihoods Program SummaryA4.pdf (Accessed February 20, 2018).

- Cocoa Livelihoods Program: TFO - Private Sector Partnerships in International Trade Development Projects - November 14, 2012. Washington, DC: WFC, 2012. Internet site: http://www.nsi-ins.ca/wp-content/uploads/2012/12/Cocoa-Livelihoods-Program. pdf (Accessed February 20, 2018).

—. Cocoa Market Update. Washington, DC: WFC, 2014. Internet site: http:// worldcocoafoundation.org/wp-content/uploads/Cocoa-Market-Update-as-of-4-12014.pdf (Accessed February 20, 2018).

—. "Our Work: Programs." 2018. Retrieved Internet site: http://www. worldcocoafoundation.org/our-work/programs/ (Accessed April 18, 2018).

Zeitlin, A., and F. Teal. Ghana Cocoa Farmers Survey 2004: Report to Ghana Cocoa Board. Oxford: Centre for the Study of African Economies, Oxford University, 2006. Internet site: http://www.gprg.org/pubs/reports/pdfs/2006-04-teal-zeitlin-maamah.pdf (Accessed February 20, 2018). 